Synthesis and characterization of mesoporous zirconium oxide thin films

This content has been downloaded from IOPscience. Please scroll down to see the full text.

2010 IOP Conf. Ser.: Mater. Sci. Eng. 12012019

(http://iopscience.iop.org/1757-899X/12/1/012019)

View the table of contents for this issue, or go to the journal homepage for more

Download details:

IP Address: 212.175.32.138

This content was downloaded on 03/07/2017 at 21:20

Please note that terms and conditions apply.

You may also be interested in:

Multi-modal mesoporous TiO2-ZrO2 composites with high photocatalytic activity andhydrophilicity Wei Zhou, Kesong Liu, Honggang Fu et al.

Preparation of macroporous zirconia monoliths from ionic precursors via an epoxide-mediated sol-gel process accompanied by phase separation

Xingzhong Guo, Jie Song, Yixiu Lvlin et al.

Effect of sputtering pressure on some properties of chromium thin films obliquely deposited

A Besnard, N Martin, C Millot et al.

Influence of Preparation Conditions on Structural Stability of Ordered Mesoporous Carbons

Synthesized by Evaporation-induced Triconstituent Co-assembly Method

Bo You, Jun Yang, Guo-ping Yong et al.

Synthesis, characterization and electrochemical properties of $\mathrm{SiO} 2-\mathrm{P} 2 \mathrm{O} 5-\mathrm{TiO} 2-\mathrm{ZrO} 2$ glass membranes as proton conducting electrolyte for low-temperature $\mathrm{H} 2 / \mathrm{O} 2$ fuel cells

G Lakshminarayana and Masayuki Nogami

$\underline{\text { Recent progress in mesoporous titania materials: adjusting morphology for innovative applications }}$ Juan L Vivero-Escoto, Ya-Dong Chiang, Kevin C-W Wu et al.

$\underline{X \text {-ray analysis of mesoporous silica thin films templated by Brij58 surfactant }}$

$S$ Fall, M Kulij and A Gibaud

Host-guest chemistry of mesoporous silicas: precise design of location, density and orientation of molecular guests in mesopores

Minoru Sohmiya, Kanji Saito and Makoto Ogawa 


\title{
Synthesis and Characterization of Mesoporous Zirconium Oxide Thin Films
}

\author{
A. Mikó ${ }^{1}$, A. L. Demirel ${ }^{1}$, M. Somer ${ }^{1}$ \\ ${ }^{1}$ Koc University, Chemistry Department, Rumelifeneri Yolu 34450 Sariyer, Istanbul, \\ Turkey \\ E-mail: amiko@ku.edu.tr
}

\begin{abstract}
Zirconium oxide $\left(\mathrm{ZrO}_{2}\right)$ has generated wide interest because of its potential in applications such as solid oxide fuel cells, catalysts and optical devices. In these applications, it is important to control the grain size of the material and increase the surface area by introducing porosity with tailored pore size. This paper presents a synthesis route for the preparation of mesoporous zirconia using spin-coating method combined with block copolymer templating evaporation induced self assembly (EISA). The hybrid mesophase was formed by zirconium oxychloride precursor $\mathrm{ZrOCl}_{2} \cdot 8 \mathrm{H}_{2} \mathrm{O}$ and Brij 700 poly-ethylene oxide based block copolymer template $\mathrm{C}_{18} \mathrm{H}_{37}\left(\mathrm{OCH}_{2} \mathrm{CH}_{2}\right)$. FT-IR and Raman measurements of the hybrid mesophase provided information on the possible intermolecular interactions between the precursor and the copolymer template. The results indicate a weak ion-dipole interaction between the inorganic precursor and the organic template after the solvent evaporation, possibly directly between the zirconium and the oxygen of the poly-ethylene oxide chain. The removal of the organic block copolymer by heat treatment resulted in mesoporous zirconia with pore size of $\sim 4-8 \mathrm{~nm}$ and crystalline grain size of $\sim 10-17 \mathrm{~nm}$. The morphology in thin films depended significantly on the solvent quality and the block copolymer concentration. Tailoring the surface morphology and the grain size resulted in super-hydrophilic mesoporous zirconia thin films in contrast to water contact angle of $50^{\circ}$ on conventional tetragonal zirconium oxide.
\end{abstract}

\section{Introduction}

The first ordered mesoporous silica synthesized by Kreste et al in 1992 [1] started a fast progress in the research field of novel porous inorganic oxides. Mesoporous materials having periodically organized porosity are candidates for applications in the field of catalysis, optics, photonics and sensors because of the increased surface area and nanocrystalline structure [2-4].

For the synthesis of mesoporous ordered metal oxides, the combination of self-assembly procedure and inorganic chemistry is essential. Mainly chemical methods such as spray coating, meniscus coating, spin-coating, dip-coating, pulsed laser deposition [5] and electrochemical deposition [6] are used for the preparation of mesoporous metal oxides [7].

Block copolymer templating with the combination of spin-coating or dip-coating offers a well controllable easy tool and allows tailoring the pore size and structure of mesoporous metal oxides [8, 9]. Block polymer templating by using nonionic surfactant can be divided into four main groups: precipitation method, liquid crystal templating, evaporation induced self assembly and nanocasting on previously formed mesoporous materials [8]. Pinnavaia et al. reported the preparation of mesoporous metal oxide using nonionic poly-ethylene oxide based copolymers [10]. The basis of this synthesis route is the precipitation of the metal precursor in oxide/hydroxide form and its H-bonding to the surfactant. The use of Pluronic type large block copolymers with the same method was reported by Zhao et al [11] for the preparation of highly ordered mesoporous silica. The other commonly used method is evaporation induced self assembly (EISA). The name derives from the preparation process 
where from a relatively dilute solution a highly ordered hybrid mesophase (this phase contains both the organic and inorganic substances before calcination) can be induced by the solvent evaporation.

Periodically ordered mesoporous zirconia thin films and bulk oxides were prepared by EISA block copolymer templating method [12-17]. In these thin films the hexagonally ordered structure tends to orient in the plane of the substrate mostly due to electrostatic, van der Waals or hydrophobic/hydrophilic attractions between the substrate and the surfactant [18].

The interaction of the inorganic precursors with the organic template in the hybrid mesophase was not discussed in detail previously, although the structure of the mesoporous oxide strongly depends on such interactions. This article reports on the characterization of the hybrid mesophase formed by $\mathrm{ZrOCl}_{2} \cdot 8 \mathrm{H}_{2} \mathrm{O}$ and Brij 700 by FT-IR and Raman spectroscopic methods and presents the evidence for the possible intermolecular interactions between the two. In addition, super-hydrophilic mesoporous zirconium dioxide thin films will be shown to be formed after the calcination of the hybrid mesophase.

\section{Experimental methods}

Poly-ethylene oxide based block copolymer Brij $700\left(\mathrm{C}_{18} \mathrm{H}_{37}\left(\mathrm{OCH}_{2} \mathrm{CH}_{2}\right)_{100} \mathrm{OH}\right)$ was purchased from Aldrich with the average molecular weight of $4670 \mathrm{~g} \mathrm{~mol}^{-1}$. Zirconium salt (oxychloride) was used as inorganic precursor. Reagent grade Zirconium(IV) oxychloride octahydrate was obtained from Riedel-de Haën. Ethanol and deionized water mixture was used for the preparation of the solutions in the $100-40$ volume $\%$ ethanol.

The solutions for thin films were prepared by dissolving $0.2-50 \mathrm{mg} \mathrm{ml}^{-1}$ polymer in ethanol or ethanol-water mixture. The zirconium salt concentration was varied between $0.1-0.25 \mathrm{M}$ in the solution. The solutions were aged for $0-2$ weeks before the samples were prepared by spin coating. The thin layers were spin coated on silica or glass substrates at room temperature, $40-60 \%$ relative humidity, rotation speed of $2000 \mathrm{rpm}$ for $120 \mathrm{~s}$ using Specialty coating system, INC. spin coater.

The calcination temperatures were chosen based on the analysis of the thermogravimetric data recorded with Seiko SSC/5200 DTA/TG instrument coupled with Mass Spectrometer Pfeiffer ThermoStar ${ }^{\mathrm{TM}}$ GSD $301 \mathrm{~T}$. The DTA/TG curves were taken in air from $25{ }^{\circ} \mathrm{C}$ to $900{ }^{\circ} \mathrm{C}$ with the heating rate of $10{ }^{\circ} \mathrm{C} \mathrm{min}^{-1}$. The as prepared and calcined films were characterized using NT-MDT Solver P47 atomic force microscope in tapping mode. The X-ray diffraction measurements were conducted by Hubert G9670 powder diffraction equipment with germanium monochromator and $\mathrm{CuK} \alpha 1$ radiation. The contact angles of the calcined samples were determined by home made set up using Digital video camera MDS 100. The $4000-400 \mathrm{~cm}^{-1}$ region of the FT-IR spectra was taken on the hybrid mesophase and the precursors as KBr discs using a Jasco FT/IR-600 Plus Spectrometer. The Raman spectra were measured with Bruker RFS 100/S FT-Raman spectrometer in the range of $3600-50 \mathrm{~cm}^{-1}$ using Nd: YAG-Laser at $1064 \mathrm{~nm}$ wavelength $(200 \mathrm{~mW})$.

\section{Results and discussion}

FT-IR and Raman Spectroscopy were done to determine the interaction at molecular level in the hybrid mesophase which is critical in understanding the formation mechanism of mesoporous zirconium oxide.

First, organic Brij 700 was dissolved in pure ethanol and then $\mathrm{ZrOCl}_{2} \cdot 8 \mathrm{H}_{2} \mathrm{O}$ was added to the solution. Following the dissolution of the inorganic salt, $0-40$ volume $\%$ water was introduced to the system. The solvent was then evaporated to form the hybrid mesophase. The same preparation steps were repeated for control samples which consisted only $\mathrm{ZrOCl}_{2} \cdot 8 \mathrm{H}_{2} \mathrm{O}$ or Brij 700 .

FT-IR and Raman data of control samples were compared with that of the hybrid mesophase. Figure 1(a) represents two characteristic FT-IR spectra of the hybrid mesophase and Brij 700 after solvent evaporation in the range of $1400-700 \mathrm{~cm}^{-1}$. The solvent was found not to affect the structure of the crystalline Brij 700. The characteristic bands were observed at the same positions as previously reported [19]. In accordance with the FT-IR results, the XRD measurements (Figure 2(a)) showed the characteristic peaks of Brij 700 and the crystalline phases in the hybrid mesophase were identified as the mixture of mainly $\mathrm{ZrOCl}_{2} \cdot 8 \mathrm{H}_{2} \mathrm{O}$ and Brij 700 . In the infrared spectrum, the hybrid mesophase shows all the bands characteristic for Brij 700 and $\mathrm{ZrOCl}_{2}$ with very small to significant shifts with respect to the pure compounds. 

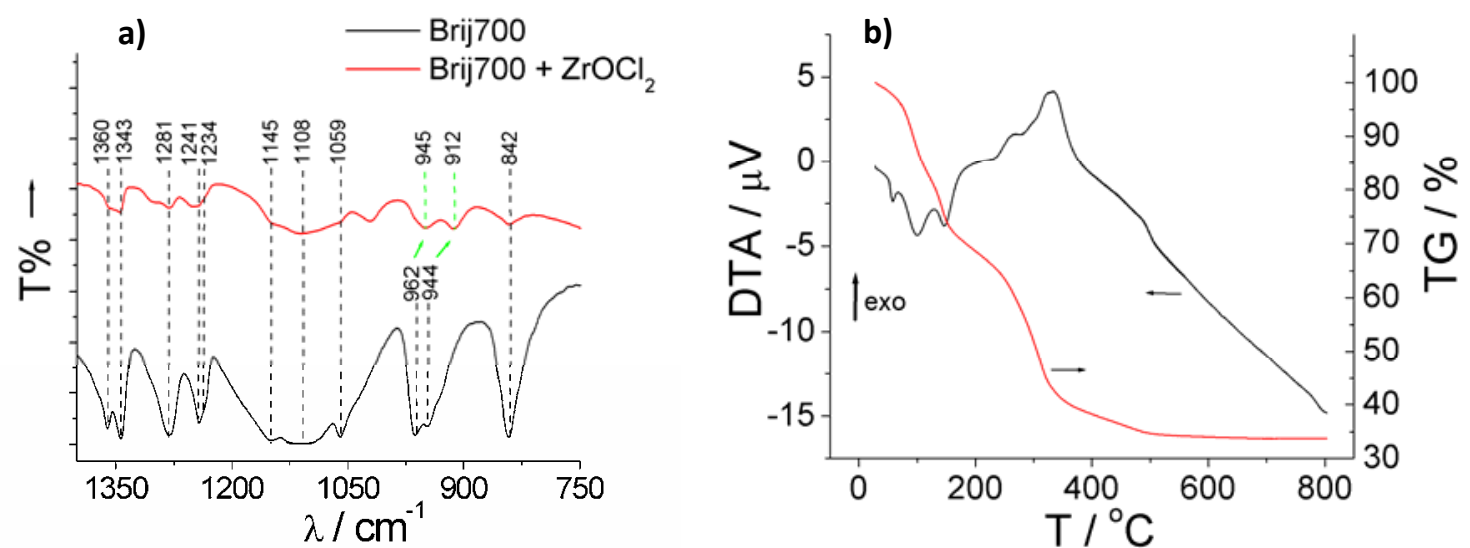

Figure 1. a) FT-IR spectra of - Brij700 and - Brij700 together with $\mathrm{ZrOCl}_{2}$ in the hybrid mesophase b) DTATG graph of Brij700 and $\mathrm{ZrOCl}_{2}$ in the hybrid mesophase

The C-O-C vibrations at 1145,1108 and $1069 \mathrm{~cm}^{-1}$ are broadened while the bands at 962 and $944 \mathrm{~cm}^{-1}$ in Brij 700 shifted to 945 and $912 \mathrm{~cm}^{-1}$ in the hybrid mesophase. This indicates that the C-O-C bond is weakened in the poly-ethylene oxide chain due to the interaction with the inorganic $\mathrm{ZrOCl}_{2}$. The analysis of the $\mathrm{Zr}-\mathrm{O}$ bands with and without Brij 700 can provide further information to understand whether $\mathrm{Zr}$ interacts directly with the organic compound in the hybrid mesophase. Therefore, the two $\mathrm{Zr}-\mathrm{O}$ Raman bands of $\mathrm{ZrOCl}_{2}$ between $350-650 \mathrm{~cm}^{-1}$ were compared with those of the hybrid mesophase. The characteristic band in the Raman spectrum (not shown) in solid $\mathrm{ZrOCl}_{2}$ at $575 \mathrm{~cm}^{-1}$ shifted to $592 \mathrm{~cm}^{-1}$ while the one at $459 \mathrm{~cm}^{-1}$ broadened in the dried hybrid mesophase. FT-IR results together with the Raman measurements thus indicated a direct interaction between $\mathrm{Zr}$ and the $\mathrm{O}$ of the poly-ethylene oxide chain. This is possible by the replacement of the water molecules in $\mathrm{ZrOCl}_{2} \cdot 8 \mathrm{H}_{2} \mathrm{O}$ and the formation of an ion-dipole interaction.

The decomposition of the Brij 700 in the hybrid mesophase and the oxide formation was followed by differential thermal analysis/thermogravimetric measurements (DTA/TG) coupled with mass spectroscopy. Figure 1(b) represents typical thermogravimetric and differential thermal analysis curves of the hybrid mesophase. All measurements showed three endothermic peaks in the DTA curves at the onset temperature of 50,70 and $130{ }^{\circ} \mathrm{C}$. The first peak is due to the melting of the polymer and did not correspond to any significant changes in the thermogravimetric data. The second and third peaks correspond to $\sim 35 \%$ mass loss which is the removal of the water from $\mathrm{ZrOCl}_{2} \cdot 8 \mathrm{H}_{2} \mathrm{O}$ and from those absorbed into the mesophase in ambient atmosphere. This was confirmed by mass spectroscopic analysis of the gas phase as well. In addition to the endothermic peaks, two exothermic peaks appeared on the DTA curve when the temperature was further increased. The first exothermic peak starts at around $280{ }^{\circ} \mathrm{C}$ and corresponds to the decomposition of the Brij 700 to $\mathrm{CO}$ and $\mathrm{CO}_{2}$ with $\sim 30 \%$ mass loss. The small shoulder on this peak indicates heterogeneous polymer structures. The second exothermic peak starts at around $480{ }^{\circ} \mathrm{C}$ and can be attributed to the change of the amorphous structure to crystalline zirconium oxide. Based on these results, the calcination temperature of the hybrid mesophase was chosen to be $450{ }^{\circ} \mathrm{C}$. The layers were heated with the ramp of $1^{\circ} \mathrm{C} \min ^{-1}$ to $450{ }^{\circ} \mathrm{C}$, kept at this temperature for 4 hours and then cooled at the same rate to room temperature. The final product was identified after complete removal of the Brij 700 by XRD data of Figure 2(a) as tetragonal $\mathrm{ZrO}_{2}$ with the crystalline grain size of $\sim 10-17 \mathrm{~nm}$. When the water content was low in the solvent mixture, very small amount of monoclinic $\mathrm{ZrO}_{2}$ formed in addition to the tetragonal major phase.

Besides the relative humidity, the percentage of water in the solvent mixture and the block copolymer concentration in the solution were the main factors which mostly influenced the pore structure of zirconium oxide. These factors were altered and optimized for the formation of mesoporous zirconium oxide. Figure 2(b) represents one characteristic AFM image of the resulting mesoporous thin film having a thickness of $150 \mathrm{~nm}$. The sample was prepared from $20 \mathrm{mg} \mathrm{ml}^{-1}$ Brij $700,0.25 \mathrm{M} \mathrm{ZrOCl}_{2} \cdot 8 \mathrm{H}_{2} \mathrm{O}$ and the mixture of $80 \%$ ethanol $20 \%$ water solution and was calcined. The ordered 2D hexagonal structure oriented in the plane of the substrate $[12,18]$. In Figure 2(b), this ordered structure appears as stripes with the diameter of $\sim 4-8 \mathrm{~nm}$ directed from lower right to upper left corner. 

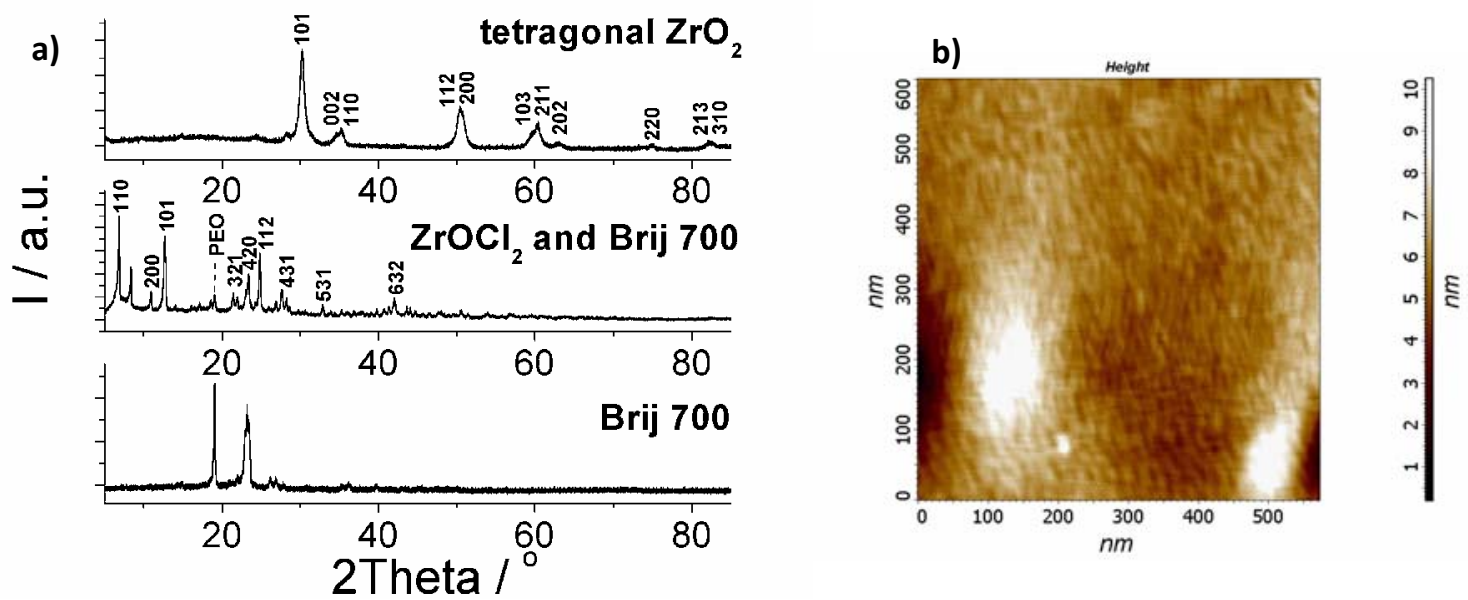

Figure 2. a) XRD data of Brij 700 (bottom), hybrid mesophase (middle) and calcined tetragonal $\mathrm{ZrO}_{2}$ (top). b) Atomic Force Microscopy height image of the $150 \mathrm{~nm}$ thick mesoporous $\mathrm{ZrO}_{2}$ film calcined at $450{ }^{\circ} \mathrm{C}$ after spin coating from $20 \mathrm{mg} \mathrm{ml}^{-1}$ Brij $700,0.25 \mathrm{M} \mathrm{ZrOCl}_{2} \cdot 8 \mathrm{H}_{2} \mathrm{O}$ solution in the mixture of $80 \%$ ethanol-20\% water.

Contact angle of water on conventional chemically stabilized tetragonal $\mathrm{ZrO}_{2}$ is $50^{\circ}$ [20]. The successful introduction of mesoporosity decreased the water contact angle to $5^{\circ}$ due to well-known surface roughness effect and resulted in super-hydrophilic films [20].

In summary, mesoporous tetragonal zirconium dioxide was successfully synthesized with ordered structure. The crystalline grain size of the layers was $\sim 10-17 \mathrm{~nm}$ while the pore size was $\sim 4-8 \mathrm{~nm}$. Based on the FT-IR and Raman measurements, a direct interaction between $\mathrm{Zr}$ and the $\mathrm{O}$ of the polyethylene oxide chain was concluded in the hybrid mesophase. The calcination of the mesophase at $450{ }^{\circ} \mathrm{C}$ resulted in super-hydrophilic $\mathrm{ZrO}_{2}$ thin films with a water contact angle of $5^{\circ}$.

Acknowledgement A. Miko acknowledges the financial support through Postdoctoral Fellowships of TÜBİTAK (Turkish Scientific and Technological Research Council) and Koç University.

\section{References}

[1] C. T. Kresge, M.E. Leonowicz, W. J. Roth, J. C. Vartuli, J. S. Beck, Nature (1992) 359.

[2] N. K. Raman, M. T. Anderson, C. J. Brinker, J. Chem Mater. 8 (1996) 1682.

[3] N. Hüsing, U. Schubert, Angew. Chem. 110 (1998) 22.

[4] F. Schüth, Chem Z. 29 (1995) 42.

[5] K. J. Balkus, A. S. Scott, M. E. Gimon-Kinsel, J. H. Blanco, Microporous Mesoporous Mater. 38 (2000) 97.

[6] G. S. Attard, P. N. Bartlett, N. R. B. Coleman, J. M. Elliott, J. R. Owen, J. H. Wang, Science 278 (1997) 838.

[7] C. Sanchez, C. Boissiere, D. Grosso, C. Laberty, L. Nicole, Chem. Mater. 20 (2008) 682.

[8] G. J. A. Soler-Illia, E. L. Crepaldi, D. Grosso, C. Sanchez, Current Op. Coll. Interf. Sci. 8 (2003) 109.

[9] B. Smarsly, S. Polarz, M. Antonietti, J. Phys. Chem. B 105 (2001) 10473.

[10] P. Tanev, T. J. Pinnavaia, Science 267 (1995) 865.

[11] D. Zhao, J. Feng, Q. Huo, N. Melosh., G. H. Fredrickson, B. F. Chmelka, G. D. Stucky, Science (1998) 279.

[12] P. Yang, D. Zhao, D. I. Margolese, B. F. Chmelka, G. D. Stucky, Nature 396 (1998) 152.

[13] E. L. Crepaldi, G. J. de A. A. Soler-Illia, A. Bouchara, D. Grosso, D. Durand, C. Sanchez, Angew. Chem. $42(2003) 347$.

[14] P. Yang, D. Zhao, D. I. Margolese, B. F. Chmelka, G. D. Stucky, Chem. Mater. 11 (1999) 2813.

[15] C. Sanchez, G. J.De A. A. Soler-Illia, F. Ribot, D. Grosso, C. R. Chimie 6 (2003) 1131.

[16] I-M. Hung, D.-T. Hung, K.-Z. Fung, M.-H. Hon, Materials Letters 62 (2008) 1147.

[17] D. Grosso, C. Boissiere, B. Smarsly, T. Brezesinski, N. Pinna, P. A. Albouy, H. Amenitsch, M. Antonietti, C. Sanchez, Nature Materials 3 (2004) 787.

[18] I. A. Aksay, M. Trau, S. Manne, I. Honma, N. Yao, L. Zhou, P. Fenter, P. M. Eisenberger, S. M. Gruner, Science 273 (1996) 892

[19] Y. Deng, J. B. Dixon, G. N. White, Colloid Polymer. Sci. 284 (2006) 347.

[20] F. Namavar, C. L. Cheung, R. F. Sabirianov, W.-N. Mei, X. C. Zeng, G. Wang, H. Haider, K. L. Garvin, Nano Letters 8 (2008) 988. 